\section{Analysis of accidents due to slope failure in Indian opencast coal mines}

\author{
A. K. Dash* \\ Department of Mining Engineering, National Institute of Technology, \\ Raipur 492 010, India
}

Opencast mining operation involves removal of bulk quantities of overburden, dumping and backfilling in excavated areas. A phenomenal increase in the share of opencast production $(93 \%)$ in Indian coal industry has resulted into significant problem of waste dumps at present with greater height of the dump constructed over minimum area and giving rise to increasing danger of dump failures. Dangerous occurrences, incidents, accidents and disasters due to dump failure in Indian opencast mines are quite common, resulting in injuries and fatalities. In 2016, a disaster due to dump failure in Rajmahal coalfield of ECL, killed 23 workers. Even though all such accidents are being analysed and recommendations made in each case, similar accidents are not prevented. Unfortunately we seem to miss the lessons each time from these past incidents or accidents. In this communication, we analyse an accident due to dump slope failure in Indian opencast coal mine, in which a giant debris flow occurred during routine mining operation. In addition, we identify the gaps in our learning system and the thrust on improving safety by analysing accidents using root cause analysis techniques and to improve the stability of the dump.

Keywords: Accidents' analysis, opencast mines, slope failure, waste dumps.

THE overburden removal is the first step in a coal mining operation in opencast mines, in order to expose the underlying coal for excavation. Opencast mining of coal and metals invariably pollutes the environment, producing large amounts of waste rock which is generally piled up into large dumps on the surface ${ }^{1,2}$. The amount of overburden or dump will increase with the increasing size of opencast mines and large stripping ratios. Coal India Limited (CIL) alone has removed 160, 462, 695, 886.528 and 1148.908 million cubic metres of overburden during the years 1986-1987, 1999-2000, 2009-2010, 20142015 and 2015-2016 respectively $^{3}$. The mining waste dump can be considered as a potential source of hazard.

Overburden material being a waste and nonmarketable product, needs to be removed, and handled safely and economically. The foremost aim for construction of an overburden dump is to provide a stable and safe working surface for waste disposal. The failure of a mass of waste material along the slope of a dump is called a dump slide.

*e-mail: ashishdash1991@gmail.com
It involves a sudden and massive downward and outward movement of the entire mass of waste or overburden. Dump slide may occur in more or less every possible manner, slowly or suddenly and with or without any apparent provocation or indication. Generally, slides are due to failure of the floor of the dump or the bottom layer due to huge load, and the failure to maintain an appropriate configuration of dump shape due to lack of available space. However, in some instances, they are caused due to increase in hydrostatic pressure or inadequate compaction or wrong sequence of dump materials.

Flat dumps with low height could be ideal from the point of stability; however, these would not only cover a lot of ground, but also prove to be costly. Hence a balance needs to be maintained between maximum slope and minimum possible ground space to be occupied, while ensuring that dumps do not slide and cause any untoward incident or accident. Overburden dumps can be internal dumps formed by in-pit dumping parallel to voids or spaces by extraction of coal, or they can be external dumps formed at a site away from the coal-bearing area ${ }^{4}$. External dumping has some serious problems like requirement of additional land, high rehandling cost, stability and reclamation at the site ${ }^{5,6}$. Even though emphasis is given on in-pit dumping practice, the concept of external dumps cannot be eliminated completely. The concept of internal dumping is used in countries like Australia, Canada and USA ${ }^{5,7}$. This technique avoids the problems of external dumping practices, including the requirement of land for dumping. On the other hand, a combination of internal and external dumps will considerably reduce the required land. As a result, it will considerably reduce the requirement of surface land ${ }^{5}$. Slope failure or dump failure is a matter of serious concern in Indian mining industry, as in recent times several slope failures have taken place in coal mines causing loss of precious lives and costly equipment ${ }^{8,9}$. It is necessary to study such cases and find out the causes of failure. In this communication, we have analysed an accident case study highlighting the root causes of failure along with the grey area in the system, suggesting recommendations for prevention.

In any industry, particularly for the safety critical industries, it is essential to carry out accident investigation and identify the thrust areas for overall improvement of safety standards. In Indian coal mines, not only disasters but also major accidents are still continuing at a disturbing rate. There is little to differentiate the failures that lead to single or multiple deaths and 'disasters ${ }^{10,11}$. On the other hand, a combination of human factors, environmental/workplace conditions and organizational failures leads to such disasters, indicating that they are mostly caused by multiple failures. Identification of all such factors plays a major role in the accident prevention approach. Hence it is important to record all the information about accidents, including causes and circumstances leading to them, and their consequences ${ }^{12,13}$. 


\section{RESEARCH COMMUNICATIONS}

Table 1. Major accidents, including disasters due to slope failure from 1901 to 2016 (ref. 3)

\begin{tabular}{|c|c|c|c|}
\hline Date of accident & Mine & Number of persons killed & Cause of accident \\
\hline 29 January 1921 & East Bagdigi & 5 & Side fall \\
\hline 16 September 1921 & Pandeybera & 5 & Side fall \\
\hline 25 January 1923 & Mahakali & 8 & Side fall \\
\hline 26 March 1923 & Bonbiddin & 4 & Side fall \\
\hline 21 June 1923 & Dhori & 7 & Side fall \\
\hline 01 September 1926 & Bararee & 4 & Side fall \\
\hline 21 October 1940 & Bhulanbararee & 6 & Side fall \\
\hline 03 December 1941 & Dhemo Main & 4 & Side fall \\
\hline 13 March 1945 & Dhemo Main & 4 & Side fall \\
\hline 13 March 1945 & Banksimula 9 and 10 pits & 8 & Side fall \\
\hline 27 December 1948 & Kargali & 4 & Side fall \\
\hline 19 May 1952 & Mithapur & 4 & Side fall \\
\hline 22 January 1953 & Sonardih & 4 & Side fall \\
\hline 15 February 1963 & Jamuna & 6 & Side fall \\
\hline 19 February 1963 & Jharkhand & 4 & Side fall \\
\hline 04 June 1963 & Kargali & 8 & Side fall \\
\hline 27 September 1968 & North Salanpur & 6 & Side fall \\
\hline 28 February 1975 & Hessalong & 6 & Side fall \\
\hline 27 July 1975 & Pannandhro Lignite & 4 & Side fall \\
\hline 09 June 1980 & Jorekuri Palasthali & 4 & Landside \\
\hline 24 June 2000 & Kawadi Opencast & 10 & Side fall \\
\hline 12 December 2008 & Jayant Opencast & 5 & Landslide \\
\hline 29 December 2016 & Rajmahal Opencast & 23 & Landslide \\
\hline
\end{tabular}

From the statistical data of major accidents, including disasters in Indian coal mining industry, it can be observed that the rate of occurrence of disasters and major accidents is a matter of serious concern. When the causes of the disasters were analysed, it was found that the frequency of disasters due to inundation, explosion and ground movement had not been controlled effectively. The most recent Rajmahal coal mine disaster in 2016 claimed 23 lives. If we consider major accidents, including disasters only due to slope failure, then there have been 23 accidents causing 143 fatalities from 1901 to 2016. Table 1 lists all the major accidents, including disasters due to slope failure from 1901 to 2016.

In this study, one coal mine accident due to slope failure has been re-examined to analyse the causes of the accident as identified by the statutory inquiry. For a crystal-clear view about the case study accident, a description along with the identified causes and recommendations of the accident is provided according to the published Inquiry Report. Subsequently, a gap analysis has been conducted to identify the gaps in the investigation, and the lessons to be learnt from the past using a prevention approach. The case study accident is analysed using the root cause analysis (RCA) techniques like 5-whys or accident causation tree to identify the root causes of the case study accident and compare them with those identified by the statutory inquiry. Towards the end, an effort has been made to highlight what we have missed and what we have learnt from the past accidents/incidents.

Three persons were working at the toe of an overburden dump of a dragline coal face, when a rib/berm at the base of the dump failed initiating a violent slide of the dump from a distance of about $135 \mathrm{~m}$ and height of about $73 \mathrm{~m}$, filling up an old decoaled area of the dragline coal face of about $62 \mathrm{~m}$ width, $150 \mathrm{~m}$ length and 16-25 m height. Two persons were buried along with the excavators in debris resulting in death due to asphyxiation.

In the course of investigation, the following causes were identified as direct causes of dump failure: Violation of rules and permission condition; the height of the dragline dump was more than $30 \mathrm{~m}$ as permitted statutorily; the dump was formed on slushy materials and not made on rough floor; an unextracted berm of $10 \mathrm{~m}$ of coal was not left below loose dragline dump between two cuts to protect the dump base as required; supervisors allowed the workers to work in such dangerous conditions, i.e. toe of the dragline dump.

During investigation only the direct causes of the accident were identified to make recommendations. However, some important links are missing in the accident investigation report.

Why design of the dump was not proper?; Were the dumps designed by a competent person having knowledge and expertise in dump design?; Why was the dump not formed on rough floor?; Was there any procedure regarding dump formation/construction?; Were proper resources provided during dump construction or not?; Was there adequate supervision during dump formation or not?; Why did the system fail to identify hazards related to wrong design of dump?; How and on what basis did supervisors allow the workers to work under such dangerous conditions, i.e. toe of the dragline dump?; Were 


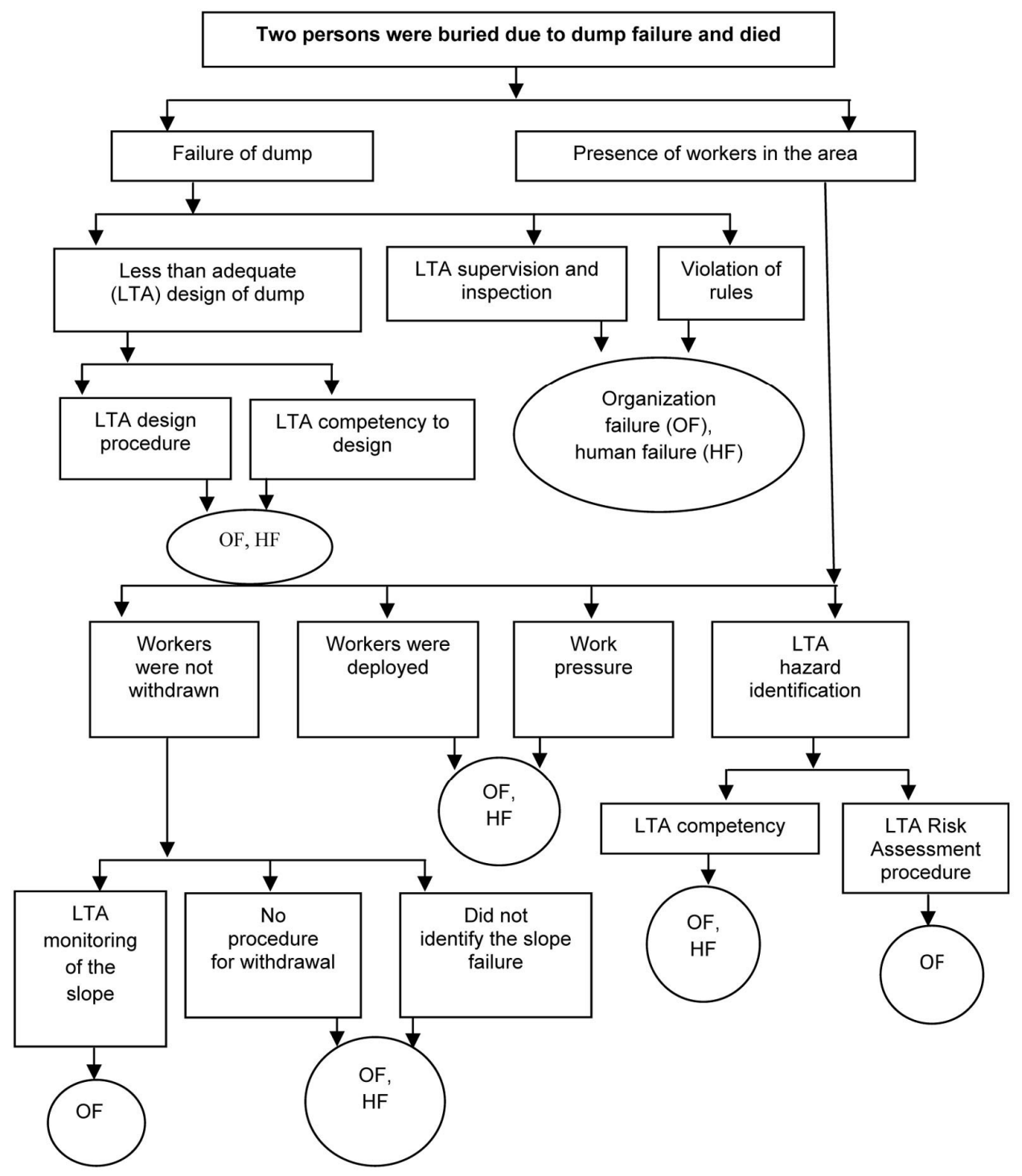

Figure 1. Accident causation tree of the case study.

the hazards identified by the supervisors and workers or not?; Was any risk assessment conducted to identify the hazards related to dump failure or not?; Was there a system of risk assessment before starting any job or not?; Was there any history of similar incidents in the mine?; Were such past incidents investigated and recommendations implemented or not?.

During analysis of the above accident case study, an accident causation tree was developed, not only to identify all the probable causes along with the root causes but also to give a clear picture about the sequence of events prior to the accident (Figure 1).

A comparison between the causes identified by the statutory inquiry and the possible and potential causes identified through application of RCA techniques like accident causation tree and 5-whys technique reveals the following.
According to the statutory inquiry, the accident took place due to (i) violation of rules and permission condition, (ii) the height of the dragline dump was more than $30 \mathrm{~m}$, (iii) the dump was not formed on rough floor and made on slushy materials, (iv) an un-extracted berm of $10 \mathrm{~m}$ of coal was not left below loose dragline dump between two cuts to protect the dump base as required, (v) dangerous workplace conditions, i.e. toe of the dragline dump was not examined by competent persons even though it was reported by supervisors.

However, root cause analysis of the accident helped identify the following causes.

Mine safety management system failed: (i) To establish standard operating procedure (SOP) for the construction of waste dump based on risk assessment; (ii) To provide effective supervision at the time of work; (iii) To provide adequate resources for slope monitoring; (iv) To establish 
procedures to ensure that workers do not enter into areas where imminent danger could be present.

All the possible hazards related to working at the toe or slope failure were ignored without any justification or risk assessment. The mine workers and management were not competent to identify the hazards or conducting risk assessment. This lack of hazard perception led to a catastrophic decision of allowing workers to work near to the toe of an active dump.

One of the causes identified by the statutory inquiry was the absence of an unextracted berm of $10 \mathrm{~m}$ of coal at the toe of the dump which resulted into failure of the dump.

Normally the slope of a dump should not exceed the angle of repose of the materials of the dump, which is usually taken to be $37.5^{\circ}$. A berm of solid coal at the bottom would have increased the slope angle more than the actual angle of repose, i.e. more than $37.5^{\circ}$. Steeper angle of dump slope due to the presence of rib would not allow the dump to take its natural shape along the angle of repose. Steeper angle of dump slope indicates stacking of more volume of waste materials for a certain height of the dump, and this would exert more pressure or stress on the berm. Once the stress exceeds the strength of the berm, there is likelihood of catastrophic failure of the dump. The provision of rib at the toe would have created a condition likely to cause failure of the dump. Hence the provision of such berm at the toe may be apparently a preventive measure against such failure, but for long-term stability such berm creates a hazardous condition for failure. The possible and potential causes as identified by the RCA technique are: (i) Failure of rib was because of the excessive pressure from dump materials. With change in the dump slope angle and increase in the height of dump, the pressure from dump materials was increased. The poor procedures like Less Than Adequate (LTA) procedure for dump construction and lack of risk assessment before developing the dumping led to sudden and massive failure of the dump. (ii) The management failed to withdraw persons from dangerous workplace as there was no such information about failure of the dump. This is because of the absence of dump monitoring system, LTA dump monitoring procedure, LTA resources (instrument and supervision) and lack of communication.

The general observations from the study are: (i) In opencast workings, the bench configurations in high wall and spoil dumps must be finalized after proper slope-stability studies. Dumping profile with minimum average factor of safety of 1.40 should be adopted. (ii) The slope of a spoil bank should be determined by the natural angle of repose of the material being deposited but, in any case, it must not exceed $37.5^{\circ}$ from the horizontal ${ }^{14}$. (iii) The movement of high-dump slopes in large opencast projects should be monitored by sophisticated dump slope-monitoring systems and surveyors should be trained in the use of such systems. (iv) Any spoil bank exceeding $30 \mathrm{~m}$ in height should be benched so that no bench exceeds $30 \mathrm{~m}$ in height and the overall slope must not exceed 1 vertical to 1.5 horizontal $^{14}$. (v) Suitable drainage system must be maintained to reduce the risk of increasing hydrostatic pressure, in turn reducing the risk of failure. (vi) No person should approach or be permitted to approach the toe of an active spoil bank where he may be endangered from material sliding or rolling down the face ${ }^{14}$. In the toe of the overburden dump which was in the active stage had been declared as 'danger area or no-go-zone', as required under 108(7) of the Coal Mine Regulation 2017 (ref. 14), this accident could have been avoided.

It is expected that implementation of the above recommendations will reduce major accidents from dump failure to a great extent.

Further analyses of the above accident case study show that the root causes for failure of the dump leading to the accident can be attributed to one or more of the following basic factors ${ }^{15-19}$ : (i) Less than adequate slope monitoring system or culture of regular slope monitoring. (ii) Lack of adequate and effective stand operating procedures for construction and maintenance of waste dump. (iii) Ineffective supervision: Management failure resulting in shortage of statutory manpower and key operators, ineffective safety organization, absence of/improper system of reporting, etc. (iv) Culture of denial ${ }^{19}$ : Poor safety culture of taking credit in getting some extra production through unsafe means, ignoring proper hazard identification and risk assessment. (v) Culture of risk assessment: less than adequate risk assessment before any routine and non-routine job.

Although numerous incidents and accidents have occurred because of lack of proper risk assessment, we have not learnt much from them. It is necessary to convince workers of all groups that risk assessment should be done before, during and after each and every routine and non-routine job and especially before all safety critical jobs and that it is not an optional extra, something that can be ignored or under work pressure. Now it is also made compulsory under our law ${ }^{14}$ and management system.

Identification of the root causes along with all possible causes through proper investigation is needed to prevent the repetition of similar accidents in opencast mines in future. The lessons learnt will not be effective, had the causes identified by RCA are not brought into the recommendation and implemented accordingly. From the analysis of the presented case study, it is clear that the accident investigation system in Indian mines is mostly rule-based and human error-centric ${ }^{10,12,14-16,20,21}$. From the case study described or similar accident/incident/ dangerous occurrences, there is a lot to be learnt ${ }^{22}$. We need to assess, identify and calculate the risk systematically before, during and after each and every routine or non-routine job to make sure that the safe method or practice has been followed. Most importantly, poor safety 
culture like taking undue risk without assessment, culture of denial, etc. should be completely eliminated from the system.

1. Wu, A., Yin, S., Wang, H., Qin, W. and Qiu, G., Technological assessment of a mining-waste dump at the Dexing copper mine, China, for possible conversion to an in situ bioleaching operation. Bioresour. Technol., 2009, 100, 1931-1936.

2. Johnson, D. B., Biohydrometallurgy and the environment: intimate and import interplay. Hydrometallurgy, 83, 153-166.

3. DGMS, The Accident Investigation Report, Directorate General of Mines Safety, Dhanbad, India, 2016.

4. Rai, P. B. and Mahapatro, S., Overburden dump slope stability: a case study at coal mine. B Tech thesis, Department of Mining Engineering, National Institute of Technology, Rourkela, Odisha, India, 2013.

5. Kainthola, A., Verma, D., Gupte, S. S. and Singh, T. N., A coal mine dump stability analysis - a case study. Geomaterials, 2011, $1,1-13$.

6. Upadhyay, O. P., Sharma, D. K. and Singh, D. P., Factors affecting stability of waste dumps in mines. Int. J. Surf. Min. Reclam., 1990, 4, 95-99.

7. Fernando, J. and Nag, D., A study of internal overburden dumps design and stability analysis for Hazelwood Power Mine, Latrobe Valley, Victoria, Australia. Application of computers and operations research in the minerals industries, South African Institute of Mining and Metallurgy, Cape Town, South Africa, 14-16 May 2003, pp. 267-274.

8. Dash, A. K., Paul, P. S. and Bhattcharjee, R. M., Accident analysis of Indian non-coal mines - need for change in focus of accident investigation. Indian Miner. Ind. J., 2014, II, 2/Q2, 47-51.

9. Dash, A. K., Bhattcharjee, R. M. and Paul, P. S., Gap analysis of accident investigation methodology in the Indian mining industry - an application of Swiss cheese model and 5-why model. IAMURE Int. J. Ecol. Conserv. Philipp., 2015, 15, 1-27.

10. Dash, A. K., Bhattacharjee, R. M. and Paul, P. S., Lessons learned from Indian inundation disasters: an analysis of case studies. Int. J. Disaster Risk Reduction, 2016, 20, 93-102.

11. Quinlan, M., Ten Pathways to Death and Disaster: Learning from Fatal Incidents in Mines and Other High Hazard Workplaces, The Federation Press, 2014.

12. Bhattacharjee, R. M., Dash, A. K. and Panigrahi, D. C., Lessons learnt from Bhatdee Coal mine explosion disaster in India using root cause analysis technique. In Proceedings of the 11th International Mine Ventilation Congress, Science Press and Springer Nature Singapore Pte Ltd, 2019.

13. Dash, A. K., Bhattacharjee, R. M. and Ahmad, A., Case study of accidents related to fall from height in Indian coal mining industry: an analysis. Int. J. Sci. Eng. Res., 2016, 7/9, 387-392.

14. The Coal Mine Regulation, 2017.

15. Dash, A. K., Paul, P. S. and Bhattcharjee, R. M., A step towards accident prevention: a pre-warning signals analysis. J. Mines Met. Fuels, 2018, 66(09), 572-575.

16. Dash, A. K., Bhattcharjee, R. M., Ahmad, A., Sagesh, K. M. R. and Singh, C. S., Mine accident investigation in India: a systems approach. J. Mines Met. Fuels, 2018, 66(10), 742-748.

17. Dash, A. K., Bhattacharjee, R. M., Singh, C. S., Ahmad, A. and Sagesh, K. M. R., A decision can be a disaster: a descriptive analysis of a case study. Int. J. Appl. Environ. Sci., 2017, 12(10), 1803-1820.

18. Dash, A. K., Bhattcharjee, R. M., Paul, P. S. and Tikader, M., Study and analysis of accidents due to wheeled trackless transportation machinery in Indian coal mines - identification of gap in current investigation system. Procedia Earth Planet. Sci., 2015, $11,539-547$.

19. Hopkins, A., A culture of denial: sociological similarities between the Moura and Gretley mine disasters. J. Occup. Health Saf., 2000, 16(1), 29-36.

20. Bhattacharjee, R. M., Dash, A. K., and Paul, P. S., Changing philosophy of accident investigation in Indian mines - need for shifting focus from human error to system error. In Proceeding of National Seminar on Surface Mining, Department of Mining Engineering, ISM, Dhanbad, 2014.

21. Turner, B. A., Man-Made Disasters, Wykeham Publications Ltd., London, UK, 1978.

22. Kletz, T., Lessons from Accidents, Butterworth-Heinemann, Oxford, 1994.

ACKNOWLEDGEMENTS. I thank the Department of Mining Engineering, National Institute of Technology, Raipur for support and the Directorate General of Mines Safety for cooperation during the course of this study.

Received 23 September 2018; revised accepted 21 February 2019

doi: $10.18520 / \mathrm{cs} / \mathrm{v} 117 / \mathrm{i} 2 / 304-308$ 